\title{
The role of clay content on the response of railway track foundations during free-to-drain cyclic changes in principal stress rotation
}

\author{
Anna Mamou ${ }^{1}$, Christopher Clayton ${ }^{1},{ }^{+}$William Powrie ${ }^{1}$ and Jeffrey Priest ${ }^{2}$ \\ ${ }^{1}$ University of Southampton, UK ( ${ }^{+}$corresponding author: wp@ soton.ac.uk) \\ ${ }^{2}$ University of Calgary, Canada
}

\begin{abstract}
This paper investigates the role of clay content on the response of railway track foundation materials during free-to-drain cyclic changes in principal stress rotation. Four sand clay mixes typical of an in situ railway track foundation were investigated, with clay contents varying from $7 \%$ to $24 \%$. It was found that increasing the clay content from $7 \%$ to $24 \%$, reduced the volumetric contraction of the mixes during cyclic shear stress increases below a cyclic shear threshold. Volumetric strain reduced with both increasing intergranular and global void ratios. Non linear regression analysis showed generally high correlations between volumetric strain and both intergranular and global void ratios, with the relationship between volumetric strain and intergranular void ratio showing less scatter.
\end{abstract}

Keywords: Hollow cylinder apparatus, cyclic tests, principal stress rotation, free-to-drain, volumetric strain, excess pore pressures, resilient stiffness, sand, silt, clay

\section{BACKGROUND}

The stress paths followed by soils below a railway track foundation involve complex changes in vertical, horizontal and shear stresses, which result in a rotation of principal stress direction (Brown, 1996). Field measurements indicate that while vertical stresses reduce with depth, horizontal stress changes become more pronounced up to a certain depth below the sleeper base before reducing at greater depths. Thus while rotation in the major principal stress direction should not affect the top layers of the railway track (ballast), it may influence the cyclic stability of the foundation layer(s). 
Laboratory studies suggest that the effects of principal stress rotation on the resilient stiffness of unsaturated sand / clay materials may be secondary (Blackmore et al 2019), but in saturated conditions, principal stress rotation may be significant (Xiao et al 2013; Cai et al 2015, 2016; Qian et al 2016; Guo et al 2017). Principal stress rotation affects both the axial strain and the resilient stiffness of sand clay mixes dominated by the sand fraction (Gräbe and Clayton 2009, 2014).

The cyclic stability of saturated sand / clay mixes depends on the shear stress remaining below a threshold level (Mamou et al 2017). The cyclic shear stress threshold was found to increase with moderate additions of clay and was higher in tests that were free-to-drain (but not necessarily fully drained) than in undrained conditions in which drainage was physically prevented. Once the cyclic shear stress threshold was exceeded, the rates of axial strain accumulation, excess pore pressure generation and stiffness degradation increased dramatically. In undrained conditions the cyclic stress threshold increased as the clay content increased from $7 \%$ to $14 \%$ by dry weight, but no further increase occurred when the clay content was then increased to 24\% (Mamou et al 2018).

The role of clay content on the stability of saturated sand clay mixes subjected to cyclic loading involving principal stress rotation has mainly been investigated for undrained conditions (Gräbe and Clayton 2009, 2014; Mamou et al 2018). In the field, however, the combination of the train speed and the consolidation characteristics (permeability and volumetric compressibility) of the soil may lead to conditions being partly drained, a potentially less onerous condition as there would be a lower build-up of pore water pressures in the soil. The effect of clay content (which will affect the consolidation characteristics of the soil) on excess pore pressure generation and resilient stiffness during free-to-drain cyclic loading are less well researched. This paper discusses the effect of clay content on the volumetric compressibility, resilient stiffness and excess pore water pressure generation during free-to-drain cyclic shear stress changes with principal stress rotation, with reference to previously unpublished data from a series of tests reported by Mamou (2013).

\section{EXPERIMENTAL METHOD}


This section describes the laboratory apparatus and materials used in this research and details the typical test procedures followed during the free-to-drain cyclic tests with principal stress rotation.

\section{Apparatus}

Laboratory tests were carried out using a hollow cylinder apparatus (HCA). Data were interpreted using the Hight et al (1983) framework of average stresses and strains. The average stresses were corrected to account for membrane restraint using the approach given by Tatsuoka et al (1986; their Equations 810). Correction for membrane penetration effects was not necessary, because the specimens were fine grained and well graded, prepared at relatively high dry densities and tested at low effective stresses.

To obtain realistic stiffness values, axial strains were measured locally on the specimen so as to exclude errors associated with the misalignment of specimen ends, bedding, and apparatus compliance (Clayton 2011). The change in the outer diameter of the specimen was measured using an LVDT attached to a radial caliper. The current inner radius, $r_{i}$, was calculated from the change in inner volume, $\Delta V_{i}$ (measured directly), assuming the specimen retained a circular cross section during deformation.

Global angular displacements were measured by the torsional actuator shaft encoder. The axial force $F$ and the torque $T$ were measured using a combined load and torque cell located at the top of the specimen. The inner and outer cell pressures and the applied back pressure were controlled and measured using GDS pressure/volume controllers. Drainage was from the bottom of the specimen only. Pore water pressures were measured independently at the top and bottom of the specimen using Druck PDCR810 pressure transducers.

\section{Materials}

Four different mixes were investigated, containing different amounts of Leighton Buzzard sand fractions B (LBSFB), C (LBSFC) and D (LBSFD); Hymod Prima Clay (HPC); and Oakamoor HPF5 silica flour silt. The sand / clay mixes replicated the gradations used on the South African Coal Line (Gräbe and Clayton 2009). The compositions of the various mixes as a percentage of the total dry 
weight, and the grain specific gravities of the aggregate constituents, are detailed in Table 1. Specimens were compacted to a target dry density of $\sim 2.15 \mathrm{Mg} / \mathrm{m}^{3}$ by varying the compaction energy and initial water content with the clay content as required (Table 2).

The effect of clay on the volumetric compressibility of the sand / clay mix is discussed in the context of both the global and the intergranular void ratios. The global void ratio $e$ is defined as the ratio of the volume of voids to the volume of solids in a soil element, and considers a void as a space occupied neither by sand nor by fine particles. The global void ratio $e_{g l o b}$ was calculated as

$$
e_{\text {glob }}=\frac{V_{\text {voids }}}{V_{\text {sand }}+V_{\text {silt }}+V_{\text {clay }}}=\frac{V_{\text {voids }}}{\frac{M_{\text {sand }}}{G_{s_{\text {sand }}} \rho_{\text {water }}}+\frac{M_{\text {silt }}}{G_{s_{\text {silt }}} \rho_{\text {water }}}+\frac{M_{\text {clay }}}{G_{s_{\text {clay }}} \rho_{\text {water }}}}
$$

where $M_{\text {sand }}, M_{\text {silt }}$ and $M_{\text {clay }}$ are the masses, and $G_{\text {sand }}, G_{\text {silt }}$ and $G_{\text {sclay }}$ are the grain specific gravities of the sand, silt and clay respectively, $\rho_{\text {water }}$ is the density of the water, and $V_{\text {voids }}$ is calculated as $V_{\text {total }}$ $V_{\text {solids }}$.

The intergranular void ratio $e_{\text {intergr }}$ for a mixed soil (Mitchell 1976) reflects the notion that up to a certain fines content, the fines occupy voids between the sand grains and do not actively participate in force transmission, hence should be treated as voids. Considering the silt, along with the clay, as "fines", the intergranular void ratio $e_{\text {intergr }}$ was calculated as

$$
e_{\text {intergr }_{A}}=\frac{V_{\text {voids }}+V_{\text {silt }}+V_{\text {clay }}}{V_{\text {sand }}}=\frac{V_{\text {voids }}+\frac{M_{\text {silt }}}{G_{S_{\text {silt }}} \rho_{\text {water }}}+\frac{M_{\text {clay }}}{G_{S_{\text {clay }}} \rho_{\text {water }}}}{\frac{M_{\text {sand }}}{G_{S_{\text {sand }}} \rho_{\text {water }}}}
$$

where the symbols have the same meanings as in Equation (1). However, the relative grain size ranges (Table 1) are such that it is not clear whether the silt forms part of the fines or part of the granular 
matrix. Considering the silt to be part of the granular matrix leads to an alternative definition of the intergranular void ratio (Eq. 3):

$$
e_{\text {intergr }}=\frac{V_{\text {voids }}+V_{\text {clay }}}{V_{\text {sand }}+V_{\text {silt }}}=\frac{V_{\text {voids }}+\frac{M_{\text {clay }}}{G_{s_{\text {clay }}} \rho_{\text {water }}}}{\frac{M_{\text {sand }}}{G_{s_{\text {sand }}} \rho_{\text {water }}}+\frac{M_{\text {silt }}}{G_{s_{\text {silt }}} \rho_{\text {water }}}}
$$

Table 2 summarizes the dry densities, water contents and global and intergranular void ratios (both definitions) for the materials with the four clay contents investigated.

\section{Test procedure}

Once saturation was confirmed with B-values in excess of 0.97 (Mamou 2013), specimens were isotropically consolidated to an effective stress of $33 \mathrm{kPa}$ to match the anticipated in situ value of a soil bellow a railway track foundation (Gräbe 2001). Thereafter, each specimen was subjected to cycles of axial stress of 0 to $30 \mathrm{kPa}$, together with cycles of shear stress of $\left|\Delta \tau_{\theta z}\right|=8.5 \mathrm{kPa}$, which corresponds to the cyclic shear stress experienced by a soil element at a depth of $1 \mathrm{~m}$ below the sleeper base (Powrie et al 2007). After approximately 700 loading cycles the shear stress magnitude increased to $\left|\Delta \tau_{\theta z}\right|=$ $11.5 \mathrm{kPa}$, while the axial stress was cycled between 0 and $30 \mathrm{kPa}$. Throughout the testing programme, the axial stress was cycled 90 degrees out of phase with the shear stress $\pm \Delta \tau_{\theta z}$, to replicate as closely as possible the stress paths experienced by soils at moderate depths below a railway line as trains pass (Yang et al., 2009; Gräbe and Clayton 2009). Tests were carried out under both free-to-drain and undrained conditions (Mamou 2013; Mamou et al 2017, 2018).

This paper reports data from free-to-drain cyclic shear stress preloading, which preceded the undrained test stage presented by Mamou et al $(2018,2019)$. Table 3 summarizes the stress cycles applied in all of the test stages reported in this paper. The first letter of each test series denotes the drainage conditions (F being free-to-drain), the second letter the type of material (A-D), and the number that follows gives the magnitude of the cyclic shear stress imposed during that stage. 
Owing to the limitations of the apparatus, the loading frequency, $f$, applied in these tests was $0.0083 \mathrm{~Hz}$ or approximately 30 cycles per hour. Field measurements below a ballasted railway line (Priest et al 2010) and numerical analyses (e.g. Powrie et al 2007) show that the dominant frequency of the loading experienced by the soil during the passage of a train reduces from the axle passing frequency at shallow depths through the bogie passing frequency to the car (bogie pair) passing frequency at a depth of about $780 \mathrm{~mm}$ from the sleeper base. Field measurements by Milne et al (2017) for trains on the UK railway network - for example a 5 car Voyager $(56.1 \mathrm{~m} / \mathrm{s})$ and a 16 car Valero $(80.8 \mathrm{~m} / \mathrm{s})$ - indicated vehicle passing frequencies in the range $2.27-3.26 \mathrm{~Hz}$. However, in terms of soil drainage, the passage of an entire train might reasonably be seen as a single loading event.

In all of the tests reported in this paper, which had one-way drainage from the base, the maximum drainage path length, $d$, was the same as the specimen height, $200 \mathrm{~mm}$. In the field measurements reported by Priest et al (2010) and numerical analyses by Powrie et al (2007), the subgrade was subjected to an increase in vertical stress of more than $10 \%$ of the applied load to a depth of $955 \mathrm{~mm}$ below the sleeper base, implying that this is a maximum drainage path length. Thus the maximum drainage path length in the laboratory tests was about $1 / 5$ of that in the field. Equality of the dimensionless group $c_{v} / f \cdot d^{2}$ between the laboratory and the field would then imply an equivalent field loading frequency of $30 \div 25=1.2$ cycles per hour. This is low, even in terms of whole train passages for a lightly used line. Thus although the excess pore pressures discussed were measured at the top of the specimen, i.e. at the furthest point from the drainage boundary, it is likely that the free-to-drain laboratory tests represent best-case field scenarios in terms of the excess pore water pressure remaining at the end of a series of cycles corresponding to the passage of a single train in the field. Results from undrained tests, which would represent the worst case for residual pore pressures after passage of a train, are discussed elsewhere (Mamou et al 2018, 2019).

\section{RESULTS AND DISCUSSION}

The effect of clay content on the volumetric compressibility of the sand clay mixes during cyclic shear stress increases is shown in Fig. 1. The free-to-drain cyclic shear stresses applied were below the cyclic 
shear stress threshold of each sand / clay mix, at which the rate of generation of strains or excess pore water pressures starts to increase dramatically. The cyclic shear stress thresholds under free to drain conditions were reported by Mamou et al (2017) as $23.5 \mathrm{kPa}, 26.5 \mathrm{kPa}$ and $29.5 \mathrm{kPa}$ for the $7 \%, 11 \%$ and $14 \%$ clay content materials respectively. For the $24 \%$ clay content it may be deduced that the cyclic shear stresses applied were below the threshold, as no acceleration in volumetric strain, excess pore pressure generation or stiffness degradation occurred. The start of each different test stage (i.e., an increase in magnitude of the applied cyclic shear stress) is indicated by the letters (a) and (b). The results during test stage (a) show that the sandier mix was the most volumetrically contractile mix, with the rate of volumetric contraction with increasing number of cycles reducing as the clay content increased from 7 to $24 \%$. During stage (b), the volumetric contraction of all the mixes was significantly smaller than at stage (a), with the rate of volumetric contraction with number of loading cycles generally being the same for all the clay contents investigated (7\% to 24\%). Most of the difference in compression between the specimens has occurred by the end of stage (a).

To investigate the effect of clay content on the volumetric compressibility of the sand / clay mixes, the volumetric strains are analysed with reference to both the global and the intergranular void ratio. Two intergranular void ratio expressions have been investigated (Equations 2 and 3), depending on whether the silt is treated as part of the fines (Eq. 2) or as part of the sand matrix (Eq. 3). In determining the global void ratio (Eq. 1), the silt and clay particles were all assumed to contribute to the volume of solids. Figure 2 shows the variation in volumetric strain with intergranular (Fig. 2a, 2b) and global (Fig. $2 \mathrm{c}$ ) void ratio at the plateau of the resilient volumetric strain for the cyclic shear stress $\pm \Delta \tau_{\theta z}=8.5 \mathrm{kPa}$ and $\pm \Delta \tau_{\theta z}=11.5 \mathrm{kPa}$.

Final (plateau) volumetric strains generally reduced with increasing intergranular and global void ratios. Non-linear regression analysis using the statistical software package Sigmaplot (Statistical Software Inc. 1994) showed generally high correlation coefficients between volumetric strain and both granular and intergranular void ratios, with the relationship between volumetric strain and intergranular void 
ratio showing slightly less scatter. Of the two definitions of intergranular void ratio, the expression treating the silt as part of the fines (Eq. 2) showed slightly higher correlation with the final volumetric strain than the expression treating the silt as part of the volume of solids (Eq. 3). (The fitted curves in Fig. $2 \mathrm{a}$ and $2 \mathrm{~b}$ for the intergranular void ratios are inverse first order polynomials, while that in Fig. $2 \mathrm{c}$ for the global void ratio is a quadratic polynomial).

Interestingly, changes in final volumetric strain are initially more sensitive to changes in the intergranular void ratio (by either definition), and then more sensitive to changes in the global void ratio. This might reflect the expectation that the finer grains would not come into contact and interact with the granular matrix until there are enough of them to do so. Two specimens (11\% and $14 \%$ clay content) have the same global void ratio but different plateau volumetric shear strains; this might indicate that the intergranular void ratio is the more useful measure.

The excess pore pressures generated at the furthest point from the drainage boundary during the cyclic shear stress increases of stages (a) and (b) are shown in Fig.3. Owing to the feedback nature of the control system, the back pressure controller could fluctuate by approximately $\pm 2 \mathrm{kPa}$. In Fig. 3 , the difference between the pore water pressure measured at the point in the specimen furthest from the drainage boundary and the back pressure controller is plotted, to eliminate the effect of the back pressure controller hunting. Before the start of a new test stage, any remaining excess pore pressures were allowed to dissipate; the drainage time required for this increased with clay content.

The results in Fig. 3 show that for the $7 \%$ and 14\% clay content mixes, no significant residual pore pressures accumulated at the furthest point from the drainage boundary (Mamou et al 2017). However, the $24 \%$ clay content mix generated significant excess pore pressures when subjected to a cyclic shear stress $\pm \pm \Delta \tau_{\theta z}=11.5 \mathrm{kPa}$, even though it was the least contractile mix. This suggests that the permeability of the mix, rather than its volumetric compressibility during cyclic shear stress changes, may become the controlling parameter for excess pore pressure generation at high clay contents. This is reinforced by the observation that, when tested undrained, the excess pore pressures generated in the $24 \%$ clay 
content mix at its cyclic shear threshold were significantly smaller than those of the $7 \%, 11 \%$ and $14 \%$ content mixes at their cyclic shear threshold (Mamou et al 2018). Although increasing the clay content from $14 \%$ to $24 \%$ increased the volumetric stability in the free-to-drain tests, it did not increase the cyclic shear stress threshold at which significant shear strains started to accumulate.

The effect of increasing the clay content on the resilient stiffness of the different sand / clay mixes during the shear stress cycles of stages (a) and (b) is shown in Figure 4. The resilient Young's modulus of the mix increased with clay content up to and including a clay content of $24 \%$, the highest investigated (Mamou et al 2017 and Table 3). For clay contents of 7\%, 11\% and 14\% the resilient Young's modulus increased with increasing shear stress, but this effect was not apparent at a clay content of $24 \%$ (Figure 4 and Table 3 ).

These results have significant implications for railway foundation design. They suggest that, without periodic drainage (between train passages), a clayey sand may accumulate residual pore pressures even if the train loading frequency and drainage path length gives essentially drained conditions at lower clay contents. In these conditions, a clayey sand may be prone to undrained fatigue failure at significantly lower cyclic shear stresses than a more permeable material that experiences effectively drained conditions.

It was shown by Mamou et al (2017) that for moderate clay contents (7\% to 14\%), the cyclic shear stress threshold is significantly higher in drained than in undrained conditions. The results presented in this paper show that for the material with a clay content of $24 \%$, the benefits of better volumetric stability are offset by the reduced permeability, which results in significant residual pore pressure buildup with increasing cyclic loading. In the field, the threshold clay content at which the benefits of improved volumetric stability are offset by the disbenefits of the reduction in permeability would be expected to depend in principle on the pattern of loading and the drainage path length; although for a given category of railway, the range of these is likely to be small. 


\section{CONCLUSIONS}

This paper has reported the effects of clay content on the stiffness of cyclically loaded, compacted granular railway formation material in free-to-drain conditions. Counter-intuitively, but in line with empirical design practice, the inclusion of moderate amounts of clay fines (up to about $24 \%$ by weight) significantly improved the performance of the typical railway formation material tested. Specifically,

a. increasing the clay content from $7 \%$ to $24 \%$ reduced the volumetric compressibility of the mix during cyclic shear stress changes below the cyclic shear stress threshold

b. the resilient Young's modulus was relatively insensitive to increases in clay content up to $14 \%$, but then increased significantly on increasing the clay content to $24 \%$ by dry weight

c. the resilient Young's modulus of the materials with $7 \%, 11 \%$ and $14 \%$ clay content increased with increasing cyclic shear stress, but at $24 \%$ clay content, no such increase was observed.

Final or plateau volumetric strains generally reduced with increasing intergranular and global void ratios. Changes in final volumetric strain were initially more sensitive to changes in the intergranular void ratio, and then more sensitive to changes in the global void ratio. This is perhaps because the finer grains do not come into contact and interact with the granular matrix until there are enough of them to do so. Two specimens (11\% and 14\% clay content) had the same global void ratio but different plateau volumetric shear strains; this might indicate that the intergranular void ratio is the more useful measure.

Volumetric strain under cyclic loading reduced with increasing intergranular and global void ratios. Non-linear regression analysis showed generally high correlation between volumetric strain and both void ratios, with the relationship between volumetric strain and intergranular void ratio showing less scatter and less potential ambiguity. Two definitions of intergranular void ratio were considered, treating the silt either as fines or as part of the granular matrix. The former showed slightly better correlation with the plateau or final volumetric strain than the latter.

Although the $24 \%$ clay content mix was the most volumetrically stable, it accumulated significant excess pore pressures at the furthest point from the drainage boundary during free-to-drain cyclic 
testing. This suggests that the permeability of the mix, rather than its volumetric compressibility, may be the controlling parameter for excess pore pressure generation, cyclic stiffness and cyclic shear stress threshold in field conditions; and that there will be a threshold clay content at which the improved volumetric stability associated with the addition of clay is offset by the reduction in material permeability.

\section{ACKNOWLEDGEMENTS}

The research was funded by the Engineering and Physical Sciences Research Council (EPSRC) through the Programme Grants Track21 (EP/H044949) and Track to the Future (EP/M025276), with support from Network Rail through the Strategic Collaborative Research Framework in Future Infrastructure Systems. Data and supplementary details supporting this study are openly available from the University of Southampton repository at https://doi.org/10.5258/SOTON/xxxxx. 
Table 1: Compositions of materials A to D (as a percentage of total dry specimen weight) as formulated by Gräbe and Clayton (2014)

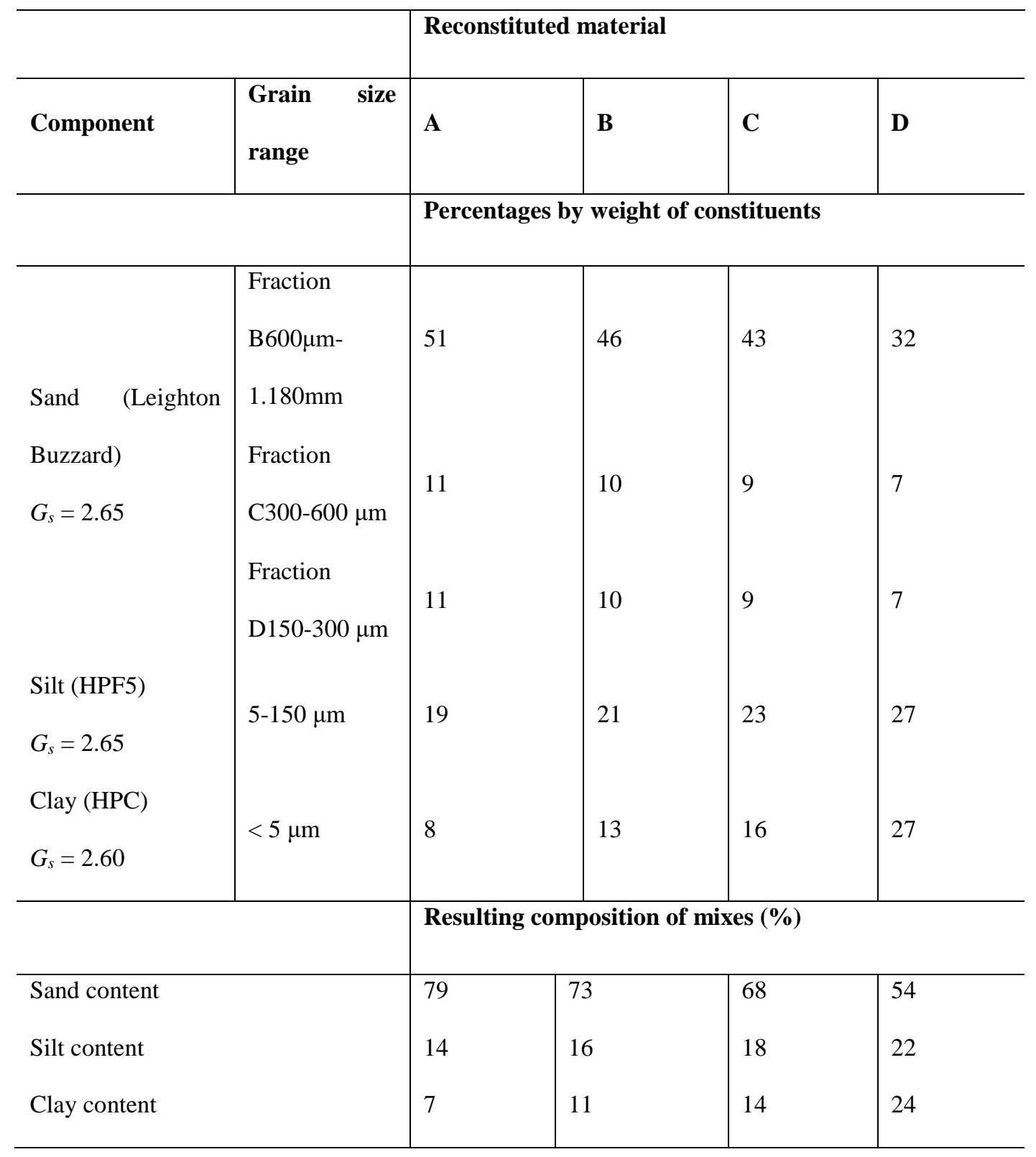


Table 2: Clay contents, water content, dry densities and corresponding global and intergranular void ratios of the investigated sand / clay mixes

\begin{tabular}{|c|c|c|c|c|c|c|}
\hline $\begin{array}{l}\cdot \frac{\pi}{\bar{d}} \\
\frac{\tilde{J}}{\Sigma}\end{array}$ & 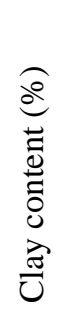 & 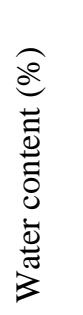 & 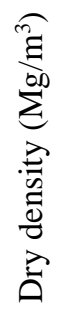 & $e_{\text {glob }}=\frac{\mathrm{v}_{\text {voids }}}{\mathrm{V}_{\text {silt }}+\mathrm{V}_{\text {clay }} \mathrm{V}_{\text {sand }}}$ & $e_{\text {intergrA }}=\frac{\mathrm{V}_{\text {voids }}+\mathrm{V}_{\text {silt }}+\mathrm{V}_{\text {clay }}}{\mathrm{V}_{\text {sand }}}$ & $e_{\text {intergr } B}=\frac{\mathrm{V}_{\text {voids }}+\mathrm{V}_{\text {clay }}}{\mathrm{V}_{\text {sand }}+\mathrm{V}_{\text {silt }}}$ \\
\hline A & 7 & 7.88 & 2.15 & 0.23 & 0.69 & 0.34 \\
\hline B & 11 & 8.31 & 2.12 & 0.25 & 0.87 & 0.44 \\
\hline $\mathrm{C}$ & 14 & 8.47 & 2.12 & 0.25 & 1.05 & 0.49 \\
\hline D & 24 & 8.61 & 2.10 & 0.26 & 1.75 & 0.73 \\
\hline
\end{tabular}

Table 3: Summary of the testing programme: free-to-drain tests

\begin{tabular}{|c|c|c|c|c|}
\hline Test & $\begin{array}{l}\text { Material type } \\
\text { (clay content) }\end{array}$ & $\Delta \tau_{\theta z}$ & $\begin{array}{l}\text { Number } \\
\text { of cycles }\end{array}$ & $\begin{array}{l}\text { Resilient modulus }^{1} \\
\text { (MPa) }\end{array}$ \\
\hline $\begin{array}{l}\text { FA8.5 } \\
\text { FA11.5 }\end{array}$ & A $(7 \%)$ & $\begin{array}{l}\Delta \tau_{\theta z}=+8.5 \rightarrow-8.5 \mathrm{kPa} \\
\Delta \tau_{\theta z}=+11.5 \rightarrow-11.5 \mathrm{kPa}\end{array}$ & $\begin{array}{l}710 \\
710\end{array}$ & $\begin{array}{l}76 \\
84\end{array}$ \\
\hline $\begin{array}{l}\text { FB8.5 } \\
\text { FB11.5 }\end{array}$ & B $(11 \%)$ & $\begin{array}{l}\Delta \tau_{\theta z}=+8.5 \rightarrow-8.5 \mathrm{kPa} \\
\Delta \tau_{\theta z}=+11.5 \rightarrow-11.5 \mathrm{kPa}\end{array}$ & $\begin{array}{l}708 \\
700\end{array}$ & $\begin{array}{l}77 \\
87\end{array}$ \\
\hline $\begin{array}{l}\text { FC8.5 } \\
\text { FC11.5 }\end{array}$ & $\mathrm{C}(14 \%)$ & $\begin{array}{l}\Delta \tau_{\theta z}=+8.5 \rightarrow-8.5 \mathrm{kPa} \\
\Delta \tau_{\theta z}=+11.5 \rightarrow-11.5 \mathrm{kPa}\end{array}$ & $\begin{array}{l}712 \\
710\end{array}$ & $\begin{array}{l}79 \\
91\end{array}$ \\
\hline $\begin{array}{l}\text { FD8.5 } \\
\text { FD11.5 }\end{array}$ & $\mathrm{D}(24 \%)$ & $\begin{array}{l}\Delta \tau_{\theta z}=+8.5 \rightarrow-8.5 \mathrm{kPa} \\
\Delta \tau_{\theta z}=+11.5 \rightarrow-11.5 \mathrm{kPa}\end{array}$ & $\begin{array}{l}700 \\
700\end{array}$ & $\begin{array}{l}98 \\
98\end{array}$ \\
\hline
\end{tabular}

\footnotetext{
${ }^{1}$ Measured at the end of each test stage
} 


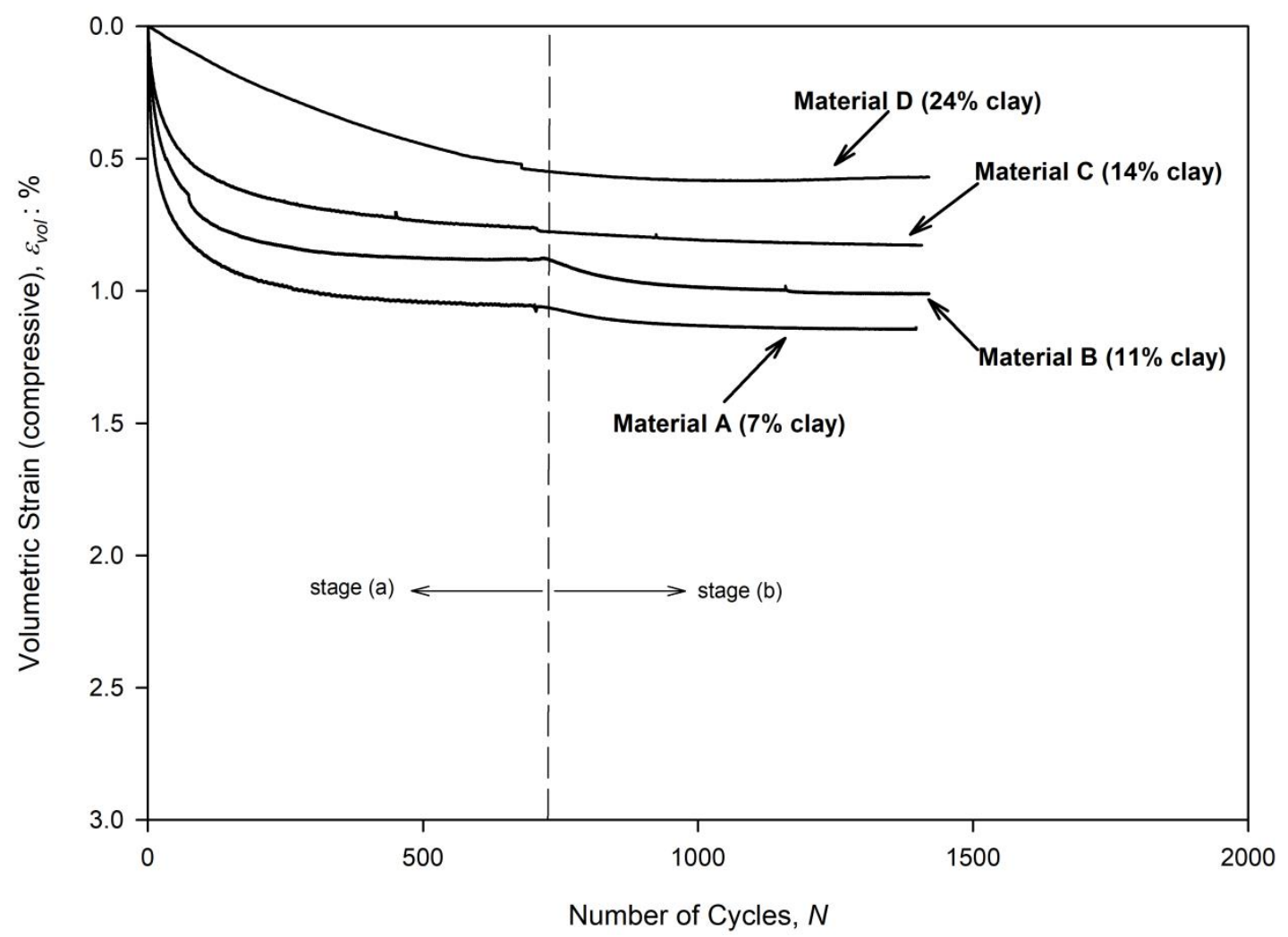

Fig. 1 Volumetric strain accumulation for materials A, B, C and D (7\%, 11\%, 14\% and 24\% clay) in free-to-drain conditions during test stage (a) at a cyclic shear stress $\pm \Delta \tau \theta_{z}=8.5 \mathrm{kPa}$ and during test stage (b) at a cyclic shear stress $\pm \Delta \tau_{\theta_{z}}=11.5 \mathrm{kPa}$ 


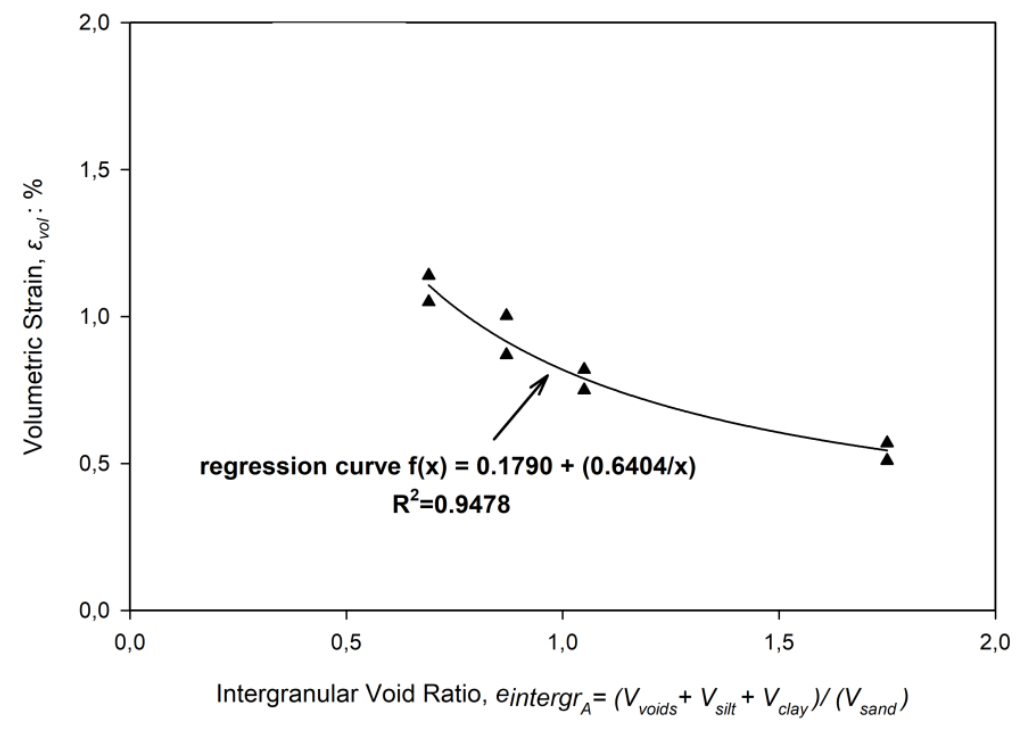

(a)

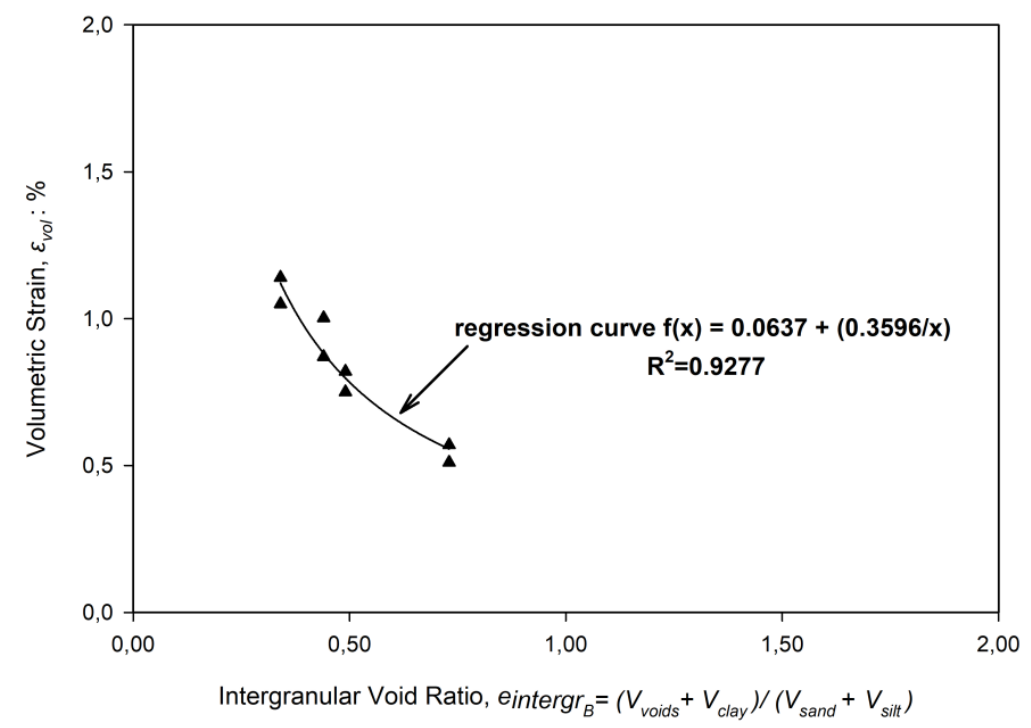

(b)

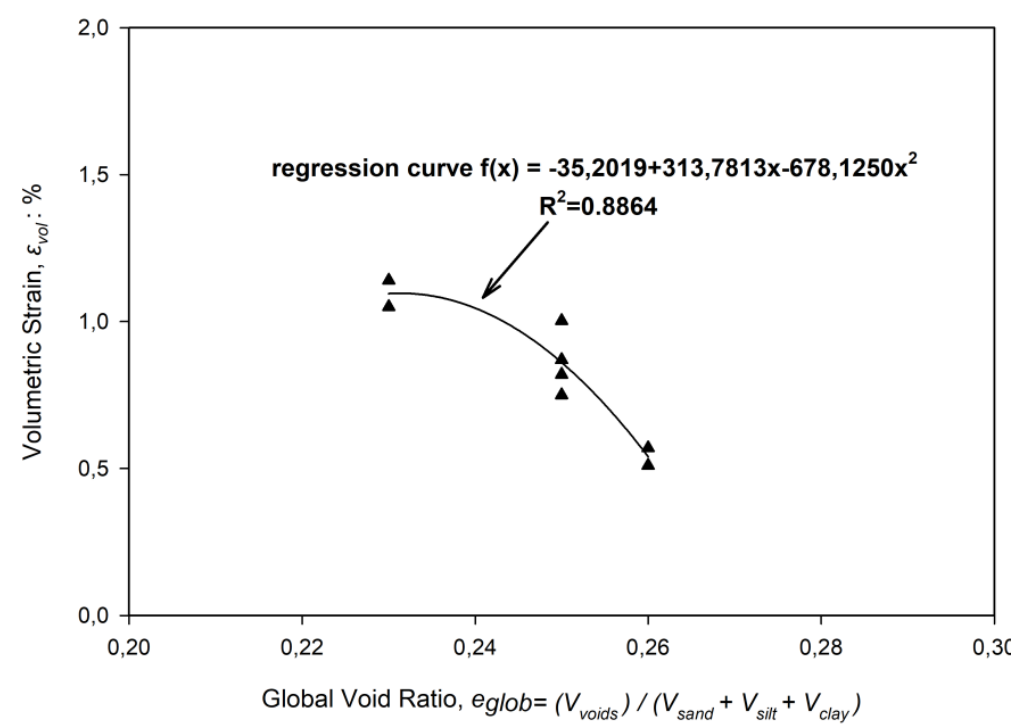

(c)

Fig. 2 The effect of increasing the intergranular $(a)(b)$ and global $(c)$ void ratios on the plateau volumetric strain of the sand / clay mixes in free-to-drain conditions during test stage (a) at a cyclic shear stress $\pm \Delta \tau_{\theta_{z}}=8.5 \mathrm{kPa}$ and during test stage (b) at a cyclic shear stress $\pm \Delta \tau_{\theta_{z}}=11.5 \mathrm{kPa}$ 

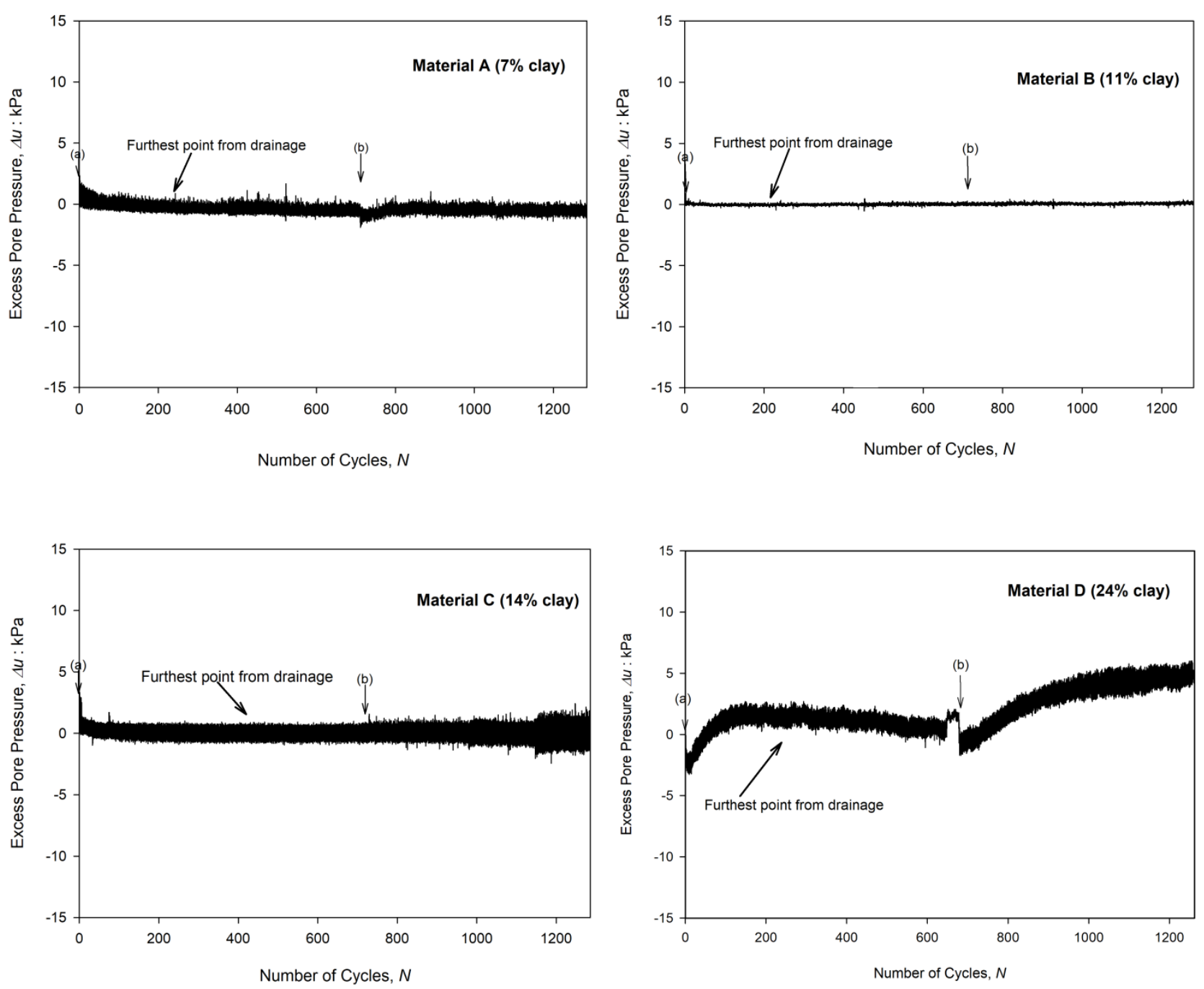

Fig. 3 Excess pore pressure accumulation at the furthest point from the drainage boundary for materials $A, B, C$ and $D\left(7 \%, 11 \%, 14 \%\right.$ and $24 \%$ clay) in free-to-drain conditions during test stage (a) at a cyclic shear stress $\pm \Delta \tau_{\theta_{z}}$ $=8.5 \mathrm{kPa}$ and during test stage $(\mathrm{b})$ at a cyclic shear stress $\pm \Delta \tau_{\theta_{2}}=11.5 \mathrm{kPa}$ 

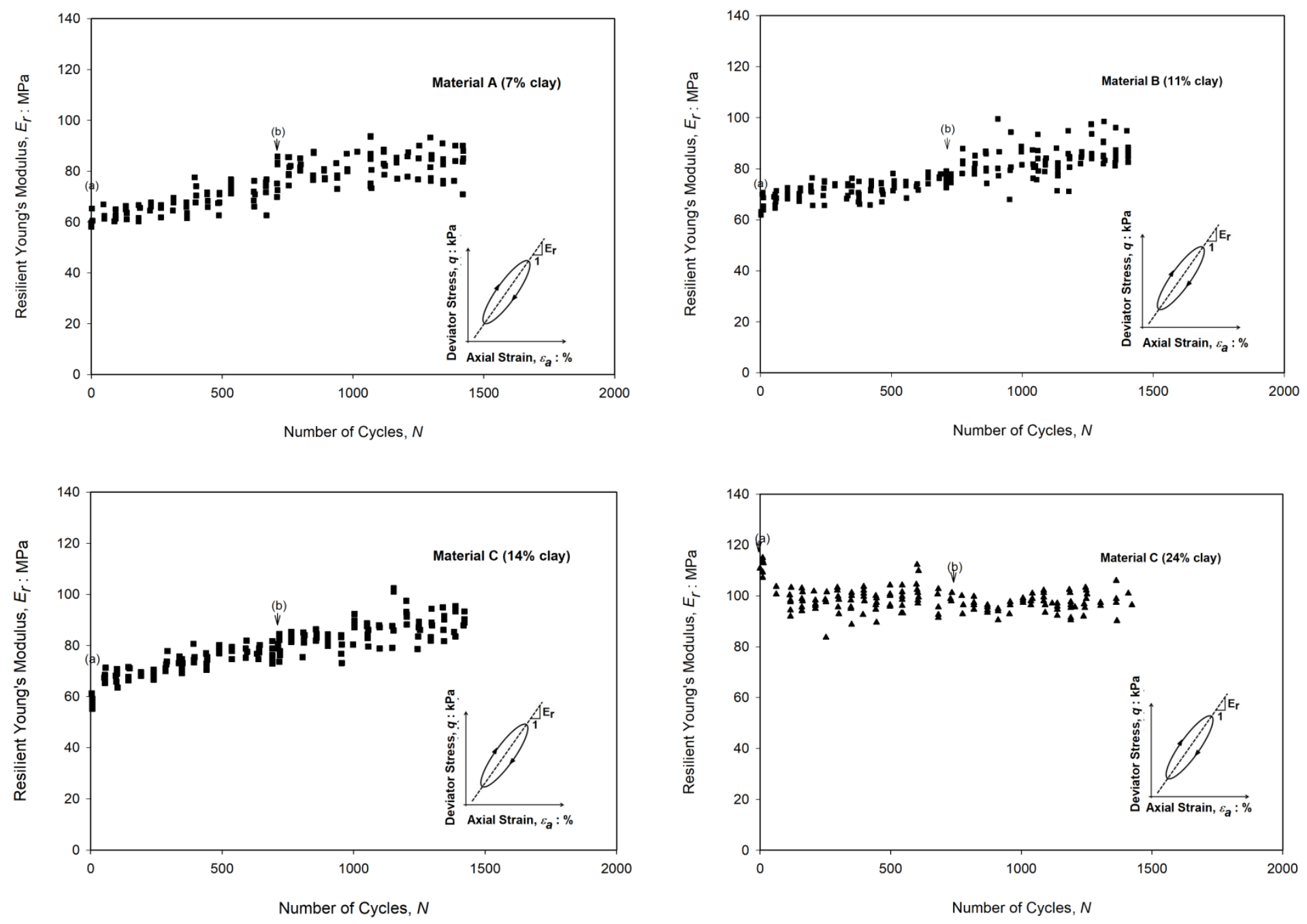

Fig. 4 Resilient stiffness changes for materials A, B, C and D (7\%, 11\%, 14\% and 24\% clay) during test stage (a) at a cyclic shear stress $\pm \Delta \tau_{\theta_{z}}=8.5 \mathrm{kPa}$ and during test stage (b) at a cyclic shear stress $\pm \Delta \tau_{\theta_{z}}=11.5 \mathrm{kPa}$ 


\section{REFERENCES}

Blackmore, L., Clayton, C.R.I., Powrie, W., Priest, J.A. and Otter, L., 2019. Saturation and its effect on the resilient modulus of a pavement formation material. Géotechnique, ahead of print

Brown, S.F. (1996). Soil mechanics in pavement engineering. Geotechnique 46, No. 3, 383-426.

Cai, Y., Sun, Q., Guo, L., Juang, C.H., Wang, J. (2015). Permanent deformation characteristics of saturated sand under cyclic loading. Canadian Geotechnical Journal 52, No. 6, 795-807.

Cai, Y.Q., Guo, L., Jardine, R.J., Yang, Z.X. and Wang, J., (2016). Stress-strain response of soft clay to traffic loading. Géotechnique $\mathbf{6 7}$, No. 5, 446-451.

Clayton, C.R.I. (2011) Stiffness at small strain: research and practice. Géotechnique 61, No. 1, 5-37.

Gräbe, P.J. (2001). Resilient and permanent deformation of railway foundations under principal stress rotation. Ph.D. thesis, University of Southampton.

Gräbe, P.J., and Clayton, C.R.I. (2009). Effects of principal stress rotation on permanent deformation in rail track foundations. Journal of Geotechnical and Geoenvironmental Engineering 135, No. 4, 555565.

Gräbe, P.J., and Clayton, C.R.I. (2014). Effects of principal stress rotation on resilient behavior in rail track foundations. Journal of Geotechnical and Geoenvironmental Engineering 140, No. 2, 1-10.

Guo, L., Cai, Y., Jardine, R.J., Yang, Z. and Wang, J., 2017. Undrained behaviour of intact soft clay under cyclic paths that match vehicle loading conditions. Canadian Geotechnical Journal, 55(1), pp.90106. 
Hight, D. W., Gens, A., and Symes, M. J. (1983). The development of a new hollow cylinder apparatus for investigating the effects of principal stress rotation in soils. Géotechnique 33, No. 4, 355-383.

Mamou, A., Powrie, W., Priest, J.A., Clayton, C.R.I. (2019). The use of the hollow cylinder apparatus to study stress paths relevant to railway track foundations, $7^{\text {th }}$ International Symposium on Deformation Characteristics of Geomaterials, Glasgow United Kingdom.

Mamou, A., Priest, J.A., Clayton, C.R.I., Powrie, W. (2018). Behaviour of saturated railway track foundation materials during undrained cyclic loading. Canadian Geotechnical Journal 55, No. 5, 689697.

Mamou, A., Powrie, W., Priest, J.A., Clayton, C.R.I. (2017). The effects of drainage on the behaviour of railway track foundation materials during cyclic loading. Géotechnique 67, No. 10, 845-854.

Mamou, A. (2013). Effects of principal stress rotation and drainage on the resilient stiffness of railway foundations. Ph.D. thesis, University of Southampton.

Milne, D.R.M., Le Pen, L.M., Thompson, D.J., Powrie, W. (2017). Properties of train load frequencies and their applications. Journal of Sound and Vibration 397, 123-140.

Mitchell, J.K. 1976. Fundamentals of soil behavior. Wiley, New York.

Powrie, W., Yang, L. A., Clayton, C. R. I. (2007). Stress changes in the ground below ballasted railway track during train passage. Proceedings of the Institution of Mechanical Engineers, Part F: Journal of Rail and Rapid Transit 221, No. 2, 247-261. 
Priest, J. A., Powrie, W., Yang, L., Gräbe, P. J., Clayton, C. R. I. (2010). Measurements of transient ground movements below a ballasted railway line. Géotechnique 60, No. 9, 667-677.

Qian, J.G., Wang, Y.G., Yin, Z.Y. and Huang, M.S., 2016. Experimental identification of plastic shakedown behavior of saturated clay subjected to traffic loading with principal stress rotation. Engineering geology, 214, pp.29-42.

Statistical Software Inc. 1994. Sigma Plot. Statistical Software Inc., San Jose, Calif.

Tatsuoka, F., Sonoda, S., Hara, K., Fukushima, S., Pradhan, T. B. S. (1986). Failure and deformation of sand in torsional shear. Soils and Foundations 26, No. 4, 79-97.

Xiao, J., Juang, C.H., Wei, K. and Xu, S. (2013). Effects of principal stress rotation on the cumulative deformation of normally consolidated soft clay under subway traffic loading. Journal of Geotechnical and Geoenvironmental Engineering 140, No. 4, 04013046.

Yang, L.A., Powrie, W. and Priest, J.A. (2009). Dynamic stress analysis of a ballasted railway track bed during train passage. Journal of Geotechnical and Geoenvironmental Engineering 135, No. 5, 680689. 